\title{
REPRESENTAÇÕES DO CONCEITO DE ECOLOGIA: ANÁLISE DE LIVROS DIDÁTICOS E CONCEPÇÃO DE ALUNOS DE CIENCIAS BIOLÓGICAS
}

\author{
Liduína Lima Pires Barbosa* \\ Andréa Pereira Silveira**
}

\begin{abstract}
Resumo: A Ecologia é uma ciência que possui diferentes definições, sendo as mais utilizadas as de Haeckel e Krebs, contrastantes do ponto de vista temporal e conceitual. Por isso propomos: i) registrar as definições de Ecologia presentes nos livros didáticos utilizados na Universidade Estadual do Ceará, Faculdade de Educação de Itapipoca UECE/FACEDI e nas escolas do ensino básico de Itapipoca-Ceará e ii) acessar as representações do termo Ecologia partilhada pelos discentes de Biologia da FACEDI que já cursaram as disciplinas de Ecologia e aqueles que ainda não as cursaram. Com uma abordagem quanti-qualitativa descritiva documental, analisamos 35 livros, 15 universitários e 20 livros do ensino básico. Para verificar quais conceitos são compreendidos pelos licenciandos utilizamos um questionário, respondido por 97 estudantes universitários e analisado pelo método de análise conteúdo. Registramos que a maioria dos livros (27) trazia apenas a definição de Haeckel e utilizavam o termo Ecologia como sinônimo de Ciências Ambientais; apenas sete livros traziam as duas definições e um trazia apenas o conceito de Krebs. Esses dados demonstram que a definição de Krebs é menos difundida do que a de Haeckel, e isso se soma a uma limitação conceitual ao considerar Ecologia como sinônimo de Ciências Ambientais, embora ambas tenham escopo distintos. Registramos também que as percepções de Ecologia partilhada pelos alunos estão mais próximas da definição de Haeckel. Concluímos que a inconsistência conceitual amplamente difundida nos livros didáticos é também partilhada pelos alunos, especialmente aqueles que ainda não cursaram as disciplinas de Ecologia.
\end{abstract}

Palavras-Chave: Ensino de Ecologia. Transposição Didática. Haeckel. Krebs.

\section{Introdução}

A Ecologia enquanto ciência pode ser entendida como "a investigação do relacionamento entre padrão, processo e teoria; onde padrão é a repetição de uma organização que não pode ser gerada somente pelo acaso; processos são as causas daqueles padrões e teorias são explicações daquelas causas" (GUREVITCH; SCHEINER; FOX, 2009). A ideia de que quanto mais perto dos trópicos maior é a variedade de estruturas, é conhecida como "gradiente latitudinal de riqueza", e é considerado o padrão ecológico mais antigo,

\footnotetext{
* Licenciada em Ciências Biológicas pela Universidade Estadual do Ceará, Campus da Faculdade de Educação de Itapipoca - UECE/FACEDI, liduina.pires@aluno.uece.br

** Doutora em Ecologia e Professora Adjunta do Curso de Ciências Biológicas da Universidade Estadual do Ceará, Campus da Faculdade de Educação de Itapipoca - UECE/FACEDI, andrea.silveira@uece.br
} 


\section{\#tear}

representando o embrião da Ecologia como uma ciência única (CIANCIARUSO et al., 2009). Contudo mesmo antes de a Ecologia existir como ciência, os humanos primitivos já estavam interessados nos padrões de distribuição de espécies para saber onde e quando seus alimentos e inimigos estavam localizados. Do ponto de vista científico, a Ecologia tem avançado pela descoberta de padrões e explicações de seus processos, mas estes só têm sentido para o avanço da Ecologia enquanto ciência se forem trabalhados à luz da teoria ecológica (MARTINS; LIMA, 2000). Para Popper, as melhores teorias são aquelas que, afirmadas com maior clareza e abrangência, melhor se expõem à crítica e à falseabilidade (POPPER, 1985).

No entanto, existem diferentes concepções acerca do que é e como se faz ciência: i) o falsificacionismo de Popper; ii) a ciência normal e as revoluções científicas de Kuhn; as ideias de Lakatos; iii) o pensamento de Feyerabend e o anarquismo epistemológico e iv) a filosofia do não de Bachelard, estão entre as correntes filosóficas discutidas entre os cientistas modernos (GERMANO, 2011). Essa diversidade filosófica deixa claro que fazer ciência não é uma atividade desvinculada do contexto social/político/cultural e não está imune aos direcionamentos da sociedade. Por isso, a compreensão do fazer ciência deve estar presente também no processo de ensinar ciência (RUFATTO; CARNEIRO, 2009), pois as duas atividades são resultado de uma construção humana, inserida em um processo histórico e social mais amplo. Essa interfase entre fazer ciência e ensinar ciência está prevista nas orientações curriculares para o ensino médio que estabelecem que a escola deve proporcionar condições para que o educando conheça os fundamentos básico da investigação científica, entendendo-a como atividade mutante e não neutra (BRASIL, 2006).

Para o ensino de Biologia está prevista por lei a inclusão da alfabetização científica na educação básica. "Esse conceito implica três dimensões: a aquisição de um vocabulário básico de conceitos científicos, a compreensão da natureza do método científico e a compreensão sobre o impacto da ciência e da tecnologia sobre os indivíduos e a sociedade" (BRASIL, 2006, p. 18). Mediados por essas reflexões acessamos o(s) conceito(s) de Ecologia presentes nos livros didáticos, bem como aquele(s) partilhado(s) pelos alunos de licenciatura em Ciências Biológicas em formação inicial.

O termo Ecologia foi citado pela primeira vez pelo biólogo alemão Ernest Heinrich Haeckel em sua obra "Generelle Morphologie der Organismen" (HAECKEL, 1866), e definido como sendo "a ciência capaz de compreender a relação do organismo com seu ambiente". Desde então o escopo da Ecologia tem apresentado modificações e dezenas de conceitos com diferentes significados têm sido a ela atribuída (PINTO-COELHO, 2000; 


\section{\#tear}

FONSECA; CALDEIRA, 2008). Isto se deve ao caráter jovem desta ciência, pois de acordo com Pinto-Coelho (2000) a Ecologia pode ser considerada uma ciência juvenil ainda sem corpo teórico rigidamente definido. Essa multiplicidade de conceitos está de acordo com o que Kuhn (2006) chamou de "os primeiros estágios de desenvolvimento de uma ciência”, que são marcados pela competição entre diversas concepções. Além disso, essa pluralidade de significados pode ser um problema para a delimitação do campo científico da Ecologia, pois segundo Santos, Escovedo e Vilela (2014) a divergência dos ecólogos ao definir Ecologia, resulta em uma dualidade de paradigmas que reforça de uma lado a Ecologia de populações e do outro a Ecologia de ecossistemas. Esses autores destacam que a existência de diferentes definições influencia na elaboração de conceitos, nos modos de produção do conhecimento e na maneira como a Ecologia é divulgada socialmente, incluindo os espaços escolares.

Em meio à heterogeneidade de significados atribuídos a Ecologia, destacam-se as definições de Haeckel 1866 e de Krebs 1972, por serem contrastantes do ponto de vista temporal e conceitual, sendo as demais definições variações destas duas. Se por um lado a definição de Haeckel deu início a Ecologia enquanto ciência, por outro lado aquela cunhada por Charles J. Krebs é considerada mais completa e atual (CAIN; BOWMAN; HACKER, 2011), quando comparada com a de Haeckel, já que para Krebs a Ecologia é definida como "o estudo científico das interações que determinam a distribuição e abundância dos organismos" (KREBS, 1972). Essa definição de Krebs incorpora o relacionamento entre padrão/processo/teoria, e incorpora o uso de previsões testáveis por meio de análises estatísticas adequadas, possibilitando a individualização da Ecologia enquanto ciência e a diferenciando da História Natural (KREBS, 2006; MENEZES; MARTINS; ARAÚJO, 2016). Baseando-se no conceito de que a ciência investiga o relacionamento entre padrão e processo, os ecólogos atuais consideram que a definição de Krebs localiza os temas centrais da Ecologia que se pautam em saber "onde os organismos ocorrem, quantos ocorrem em um determinado local e por quê?" e a utilizam em suas obras (BEGON; TOWNSEND; HARPER, 2007; CAIN; BOWMAN; HACKER, 2011). Analisando as visões de Begon e Cain acerca destas duas diferentes definições de Ecologia, postulamos que a presença exclusiva da definição de Haeckel nos livros didáticos de Ecologia e/ou Biologia, além de desatualizada, pode também incorrer em confusões relacionadas ao arcabouço teórico-metodológico e aos limites da Ecologia enquanto ciência individualizada. Para Cain, Bowman e Hacker (2011) por exemplo, a Ecologia é frequentemente confundida com as Ciências Ambientais, embora, a Ecologia 
seja um ramo da Biologia com escopo e métodos particulares, e a Ciência Ambiental seja um campo interdisciplinar que incorpora conceitos das Ciências Naturais e das Ciências Sociais.

Se por um lado, Cain, Bowman e Hacker (2011) pontuam que a Ecologia pode ser erroneamente confundida com as Ciências Ambientais, por outro lado, Correia (2014) destaca que a Educação Ambiental também está sendo equivocadamente confundida com o ensino de Ecologia. Isto fornece evidências de que as confusões conceituais são difundidas nos livros didáticos de diferentes níveis de ensino e podem ser partilhadas pelos alunos se o professor se limitar a transmitir o conteúdo do livro didático escolhido e não estimular um olhar crítico dos alunos sobre esses conhecimentos. Isso ocorre porque, em muitas escolas públicas brasileiras, os livros didáticos são as principais fontes de estudo e pesquisa disponíveis nas bibliotecas e utilizados por professores e alunos (VASCONCELOS; SOUTO, 2003, KRASILCHIK, 2008, VOICHICOSKI; MORALES, 2011; SILVEIRA et al., 2013). Assim, a inexistência dessa abordagem nos livros didáticos pode resultar em visões distorcidas a respeito destas ciências.

Motivados por estas constatações, surgiram os seguintes questionamentos: A definição de Ecologia de Krebs apesar de mais completa e atual é tão difundida nos livros didáticos quanto a de Haeckel? Entre os alunos de Ciências Biológicas quais os conceitos mais presentes? Para responder a essas questões propomos: 1) registrar as definições de Ecologia nos livros didáticos de Ecologia e Biologia Geral, utilizados por alunos e professores de licenciatura em Ciências Biológicas da Universidade Estadual do Ceará, Campus da Faculdade de Educação de Itapipoca UECE/FACEDI e aquelas presentes nos livros didáticos adotados pelas escolas de ensino básico de Itapipoca-Ceará; 2) acessar as representações do termo Ecologia partilhada pelos alunos universitários que já cursaram as disciplinas de Ecologia e aqueles que ainda não cursaram tais disciplinas. Aqui utilizamos o termo "representação" como a externalização do que o indivíduo percebe por vias fisiológicas e, como é influenciada por aspectos psicológicos e culturais (SILVA; ALBUQUERQUE, 2014).

\section{Abordagem Metodológica}

A pesquisa é de finalidade básica e natureza quantitativa combinada com uma abordagem qualitativa. Para Malheiros (2011), a pesquisa de natureza básica busca novos conhecimentos sem finalidade de uso prático imediato, mas contribui para o avanço das ciências como um todo. Quanto ao objetivo, essa pesquisa tem o caráter de análise descritiva, uma vez que consiste em descrever uma realidade, onde os fatos são observados, registrados, analisados e interpretados. Para Moreira e Caleffe (2006), o valor desse tipo de pesquisa 


\section{\#tear}

baseia-se na premissa de que os problemas podem ser solucionados e as práticas melhoradas por meio da observação minuciosa da análise e da descrição.

A pesquisa foi realizada em duas etapas: 1) levantamento documental, para saber quais as representações do conceito de ecologia em uma amostra de livros didáticos utilizados no ensino universitário e básico e 2) Levantamento descritivo para identificar quais as representações do termo ecologia na concepção dos alunos de Ciências Biológicas da Universidade Estadual do Ceará, Faculdade de Educação de Itapipoca/UECE-FACEDI.

\subsection{Levantamento documental nos livros didáticos}

Para saber se a definição de ecologia de Krebs 1972 é tão presente em livros didáticos quanto a Haeckel 1866, nós compilamos os conceitos de ecologia trazidos nos livros didáticos universitários e da educação básica. A escolha das definições de Ecologia de Haeckel e de Krebs deve-se aos seguintes aspectos: 1) estas definições são contrastantes do ponto de vista temporal e conceitual, e as demais definições são variações destas duas e 2) elas ilustram muito bem a frequente confusão da Ecologia com as Ciências Ambientais e o habitual (des) conhecimento dos conceitos e escopo da Ecologia enquanto ciência.

Utilizamos como critério de seleção os livros de Ecologia e Biologia Geral, publicados em língua portuguesa, e disponíveis nos acervos da biblioteca da UECE-FACEDI; do Laboratório de Prática de Ensino LAPEN-FACEDI; bem como aqueles do acervo pessoal dos autores deste trabalho. Os livros de Biologia Geral e Ecologia são utilizados nas disciplinas obrigatórias e optativas do curso de Ciências Biológicas e os livros do ensino básico são adotados na rede básica de ensino de Itapipoca.

Para a análise dos livros didáticos nós realizamos a leitura na íntegra do assunto abordado (conceito, definição e escopo da Ecologia) e categorizamos as definições encontradas em dois conceitos: 1) Haeckel e 2) Krebs. Enquadramos as definições dos livros analisados nestes dois conceitos, independente de estarem explicitadas suas autorias. Assim quando o autor expressava a definição de Ecologia, mas não citava o autor da definição, categorizamos a definição ou no conceito de Haeckel ou no conceito Krebs, sempre que estes

fossem correspondentes. Transcrevemos os trechos que continham as definições e abrangência de Ecologia, e inserimos algumas destas definições ao longo do texto para ilustrar e facilitar a compreensão dos resultados. 


\section{\#tear}

2.2 Levantamento descritivo com alunos universitários

Para verificar qual(is) conceito(s) de ecologia são compreendidos por alunos do curso de Licenciatura em Ciências Biológicas da UECE/FACEDI, utilizamos questionários como instrumento de coleta de dados com itens objetivos e subjetivos referentes ao conceito, entendimento e escopo de Ecologia. O questionário foi aplicado aos estudantes de Biologia de todos os semestres que se disponibilizaram a contribuir com o desenvolvimento da pesquisa. O questionário foi respondido de forma direta e presencial por 97 alunos, correspondendo a $85 \%$ dos alunos regularmente matriculados no semestre letivo de 2015.2. Ao desenvolver a pesquisa com a participação de universitários dos diferentes semestre letivos, objetivamos verificar as concepções ecológicas entre estudantes que trazem apenas o conhecimento de Ecologia da Educação Básica e aqueles que já cursaram a(s) disciplina(s) de Ecologia.

As respostas foram categorizadas para melhor compreender o que os alunos quiseram transmitir através da escrita, procedimento orientado pelo método de análise de conteúdo de Bardin (2011). As categorias podem ser estabelecidas antes do trabalho de campo, na fase preparatória da pesquisa (a priori), ou a partir da leitura de dados (a posteriori). A primeira refere-se às categorias construídas antes mesmo de verificar as informações contidas no corpo do texto. A segunda é referente a um processo de comparação e constatações presentes entre as unidades de análise, onde o pesquisador vai organizando conjuntos de elementos semelhantes. No caso desse trabalho, a categorização dos dados coletados com o questionário ocorreu tomando por base as duas formas: categorias estabelecidas antes da coleta dos dados (a priori) e categorias que emergiram da coleta de dados (a posteriori).

Considerando que esta pesquisa tem uma abordagem quanti-qualitativa, as descrições envolveram tabelas e gráficos onde foram computados os percentuais das categorias, bem como foram utilizadas transcrições das respostas com destaque em aspas e com as autorias preservadas. Os participantes assinaram o termo de consentimento livre e esclarecido e foi reservado o direito de desistência em qualquer momento da pesquisa, bem como o seu anonimato, como recomendado pela resolução 196/96, do Comitê de Ética em Pesquisa (MINISTÉRIO DA SAÚDE, 2008).

\section{Refletindo acerca dos conceitos de Ecologia}

3.1 Representações do conceito de Ecologia em uma amostra de livros didáticos

Analisamos 35 livros dos quais 15 eram universitários e 20 do ensino básico. Como o livro mais antigo datava de 1979, posterior ao conceito de Krebs 1972, esperávamos encontrar 
tanto a definição de Haeckel quanto a de Krebs. Contrário à nossa expectativa, registramos as duas definições apenas em livros universitários (7 livros - 20\% dos livros analisados). Por outro lado, a grande maioria (27 livros - 77\% do total de livros) trazia apenas a definição de Haeckel, dos quais vinte (20) são do ensino básico, ou seja, 100\% dos livros do ensino básico analisados. Destoando desse padrão, registramos na obra de Gotelli a presença exclusiva do conceito de Krebs, sem nenhuma referência ao conceito de Haeckel (Tabela 1).

Além do predomínio e exclusividade do conceito de Haeckel, registramos também que o termo Ecologia é usado como sinônimo de Ciências Ambientais na maioria dos livros analisados. Para exemplificar como a utilização exclusiva do conceito de Haeckel, contribui para a confusão conceitual relativa à definição, métodos, objetivos e abrangência da Ecologia, seguem trechos retirados das obras analisadas:

O termo ecologia foi proposto por Haeckel para designar as relações que estabelecem entre uma espécie de ser vivo e o meio que o cerca. E por meio, como já se viu anteriormente devemos entender o conjunto de todas as condições não só químicas e físicas, mas também as relações sociais que ocorrem entre esta espécie e os demais seres vivos (CELSO, 1985, p.51).

Como um campo reconhecidamente distinto da ciência, a ecologia data de cerca de 1900, mas foi apenas na última década que a palavra entrou para o vocábulo comum... Embora a ecologia permaneça radicada na biologia, ela já ganhou a maioridade com uma disciplina integrada essencialmente nova, que une os processos físicos e biológicos e serve de ponte entre as ciências naturais e as ciências sociais (ODUM, 1988, p.2).

O termo Ecologia (do grego, oikos, casa, e logos, ciência), originalmente empregado em 1866 pelo zoólogo alemão Ernst Haeckel, designa o estudo das relações entre os seres vivos e o ambiente em que vivem. Trata-se de uma ciência multidisciplinar, que engloba diversos ramos do conhecimento. Além da Biologia, da Física e da Química, também as ciências econômicas e sociais têm de ser integradas para que se possa entender a complexidade das relações entre a humanidade, os outros seres vivos e o planeta (AMABIS; MARTHO, 2010, p. 230).

Por outro lado, quando os autores adotavam o conceito de Krebs isoladamente ou em conjunto com o de Haeckel, estes apresentavam delimitações atualizadas da Ecologia enquanto Ciência distinta das Ciências Ambientais. Para exemplificar as diferenças entre a Ecologia e as Ciências Ambientais, destacamos trechos de livros universitários:

\footnotetext{
Muitos alunos se matriculam na minha disciplina esperando ouvir falar de baleias, aquecimento global e destruição das florestas tropicais. Em vez disso, eles se deparam com o crescimento exponencial, tempo de duplicação e taxas de crescimento per capita. Os estudos de ecologia dependem de medições da distribuição e abundância na natureza, portanto precisamos da matemática e da estatística como ferramentas para sintetizar e interpretar estas medições (GOTELLI, 2007, p. XIII).
} 
O que não é ecologia é militância ambiental ou ativismo político, embora, algumas vezes, os ecólogos sejam ativistas ambientais em suas vidas pessoais, e estes possam depender de pesquisa ecológica. A ecologia não trata dos sentimentos das pessoas a respeito da natureza, embora os ecólogos possam ter fortes sentimentos sobre o que estudam. No entanto, a ecologia é, de fato, uma ciência, e opera como outras disciplinas científicas (GUREVITCH et al., 2009, pg.1).

O termo ecologia, quando usado por ecólogos, se refere a uma atividade científica. Enfatizamos esse ponto porque ecologia tem outros significados em seu uso público. As pessoas não cientistas podem entender que o ecólogo é um ativista político. Alguns ecólogos são ativistas, mas muitos não o são. Além disso, como disciplina científica, a ecologia está relacionada a - embora diferente de - outras disciplinas como a ciência ambiental. Comparadas à ecologia, as ciências ambientais se concentram mais especificamente em como o ser humano afeta o ambiente e em como podemos resolver os problemas ambientais. Enquanto um ecólogo pode examinar a poluição como um dos vários fatores que influenciam o sucesso reprodutivo de plantas de áreas úmidas, um cientista ambiental pode tentar desenvolver um novo processo industrial que cause menos poluição" (Cain, BOWMAN; HACKER, 2011, p. 8-9).

Tabela 1 - Definições de ecologia de Haeckel $(\mathrm{H})$ e Krebs (K), registradas nos livros (L) disponíveis na: Biblioteca da Faculdade de Educação de Itapipoca (1), Laboratório de Prática de Ensino (2) e Acervo pessoal dos autores (3). Números de 1-15 são livros universitários e 16-35 são do ensino básico da sede do município de Itapipoca-Ceará.

\begin{tabular}{|c|c|c|c|}
\hline LIVROS DIDÁTICOS & $\mathrm{H}$ & $\mathrm{K}$ & $\mathrm{L}$ \\
\hline 1. CHARBONNEAU, J.P. et al. Enciclopédia de Ecologia. 1979. & $\mathrm{X}$ & & 1 \\
\hline 2. FERRI, M. G. Ecologia Geral. 1980. & $\mathrm{X}$ & & 1 \\
\hline 3. CELSO, M. Biogeografia e Ecologia. 1985. & $\mathrm{X}$ & & 1 \\
\hline 4. ODUM E.P. Ecologia. 1988. & $\mathrm{X}$ & & 1 \\
\hline 5. CURTIS, H. Biologia. 1997. & $\mathrm{X}$ & $\mathrm{X}$ & 1 \\
\hline 6. GRISI, B.M. Glossário de ecologia e ciências ambientais. 2000. & $\mathrm{X}$ & & 1 \\
\hline 7. PINTO-COELHO, R.M. Fundamentos em ecologia. 2000. & $\mathrm{X}$ & $\mathrm{X}$ & 1 \\
\hline 8. RICKLEFS, R.E. A Economia da Natureza. 2003. & $\mathrm{X}$ & & 1 \\
\hline 9. PURVES, W.K. et al. Vida. Vol. II. 2005. & $\mathrm{X}$ & $\mathrm{X}$ & 1 \\
\hline 10. TOWNSEND C.R. et al. Fundamentos em Ecologia. 2006. & $\mathrm{X}$ & $\mathrm{X}$ & 1 \\
\hline 11. BEGON, M. et al. Ecologia: de indivíduos a ecossistemas. 2007. & $\mathrm{X}$ & $\mathrm{X}$ & 1 \\
\hline 12. GOTELLI, N. J. Ecologia. 2007. & & $\mathrm{X}$ & 3 \\
\hline 13. MAYR, E. Isto é biologia: a ciência do mundo vivo. 2008. & $\mathrm{X}$ & & 1 \\
\hline 14. GUREVITCH, J. et al. Ecologia Vegetal. 2009. & $\mathrm{X}$ & $\mathrm{X}$ & 3 \\
\hline 15. CAIN, M.L. et al.Ecologia. 2011. & $\mathrm{X}$ & $X$ & 3 \\
\hline 16. LOPES, S. Bio3 Genética, Evolução e Ecologia. 1992. & $\mathrm{X}$ & & 1 \\
\hline 17. MARCONDES, AC; LAMMOGLIA, DA. Biologia ciência vida. 1994. & $\mathrm{X}$ & & 2 \\
\hline 18. CÉSAR; SEZAR. Biologia.1995. & $\mathrm{X}$ & & 2 \\
\hline 19. SOARES, J.L. Biologia. 1997. & $\mathrm{X}$ & & 2 \\
\hline 20. UZUNIAN, A; BIRNER, E. Biologia 3. 1997. & $\mathrm{X}$ & & 2 \\
\hline 21. LAURENCE, J. Biologia origem da vida e ecologia. 1999. & $\mathrm{X}$ & & 2 \\
\hline 22. MARCZWSKI. M. Ciências biológicas. 1999. & $\mathrm{X}$ & & 2 \\
\hline 23. PAULINO, W.R. Biologia Atual. 2000. & $\mathrm{X}$ & & 2 \\
\hline 24. SOARES, J.L. Biologia. 2000. & $\mathrm{X}$ & & 2 \\
\hline 25. AMABIS, J. M.; MARTHO, G. R. Conceitos de biologia. 2001. & $\mathrm{X}$ & & 2 \\
\hline 26. FROTA-PESSOA, O. Os caminhos da vida. 2001. & $\mathrm{X}$ & & 2 \\
\hline 27. GOWDAK, D; MARINS E. Coleção ciências, novo pensar. 2002. & $\mathrm{X}$ & & 2 \\
\hline 28. LINHARES, S; GEWANDSZNAJDER, F. Biologia hoje. 2003 & $\mathrm{X}$ & & 2 \\
\hline 29. CÉSAR; SEZAR. Biologia. 2005. & $\mathrm{X}$ & & 3 \\
\hline
\end{tabular}


30. GEWANDSZNAJDER, F. Ciências: planeta terra. 2006.

$\mathrm{X} \quad 2$

31. CRUZ, J.L.C. Projeto Araribá. Ciências. 2007.

$\mathrm{X} \quad 2$

32. AMABIS, J. M.; MARTHO, G. R.. Biologia das Populações. 2010.

$\mathrm{X} \quad 3$

33. SANTOS, F. S. et al. Biologia ser protagonista. 2010.

34. GEWANDSZNAJDER, F. Ciência: planeta terra. 2013.

$\mathrm{X} \quad 3$

35. PENA. M. Biologia pré-universitário anual. 2014.

$\begin{array}{lll}X & 3 \\ X & 3\end{array}$

X 3

Fonte: Elaborado pelas autoras

Foi possível perceber que a definição de Haeckel estabelece relação entre a Ecologia e Ciência Ambiental, e que os autores adeptos desta definição, consideram estes termos como sinônimos (CELSO, 1985; ODUM, 1988; AMABIS; MARTHO, 2010). Por outro lado, percebemos com a definição de Krebs e com os comentários de seus adeptos que a Ecologia possui escopo distinto das Ciências Ambientais (BEGON; TOWNSEND; HARPER, 2007; GOTELLI, 2007, GUREVITCH et al., 2009; CAIN; BOWMAN; HACKER, 2011).

Mesmo no nível universitário existe dificuldade em entender a delimitação da Ecologia enquanto Ciência. Isto pode limitar o desenvolvimento e o avanço da Ecologia enquanto ciência. Martins e Lima (2000) pontuam que as dificuldades que os integrantes dos programas de pós-graduação têm em reconhecer a identidade intelectual e desenhar os contornos que definem a abrangência da Ecologia, são um dos quatro fatores limitantes do desenvolvimento da Ecologia no Brasil. Os outros três fatores são: a restrita contribuição dos ecólogos brasileiros para desenvolvimento teórico da Ecologia; o envolvimento de profissionais sem formação ecológica e; a necessidade de uma abordagem que coadune teoria ecológica, conhecimento interdisciplinar e resolução de problemas ambientais.

A análise de erros e limitações conceituais nos livros didáticos tem sido foco de diversos estudos, a exemplo do levantamento bibliográfico das pesquisas entre 2000 e 2010 acerca da relação entre Educação Ambiental e livro didático realizado por Voichicoski e Morales (2011). Para esses autores é possível encontrar no livro didático pontos positivos e negativos, portanto, ele pode tanto auxiliar os professores e alunos, como pode também limitar o processo de ensino e aprendizagem. Partilhando dessa inferência, consideramos que a omissão de definições atualizadas do conceito e escopo da Ecologia, pode comprometer o processo de ensino-aprendizagem, especialmente se o professor se limitar a utilizar só o livro didático como fonte de pesquisa.

Ecologia e Ciências Ambientais operam com modelos conceituais distintos, cada qual elaborado de acordo com os pressupostos epistemológicos de seus campos particulares de atuação (CAIN; BOWMAN; HACKER, 2011). Os conceitos ecológicos são sujeitos a mudanças, pois à medida que as estruturas das teorias se tornam insatisfatórias, outras teorias 
são criadas a partir de novas bases conceituais, e isso se reflete nas diversas definições de Ecologia (MARTINS; LIMA, 2000). As Ciências Ambientais, por outro lado, não se limitam ao estudo da natureza biológica, mas operam também com dimensões sociais, políticas, econômicas e culturais (SILVA; EL-HANI, 2014). Formar profissionais e, principalmente, professores preparados para se posicionar crítica e reflexivamente, perpassa por entender e discutir diferenças conceituais. Essa preocupação se justifica, quando percebemos que a relação entre Ecologia e Ambientalismo se tornou tão próxima a ponto de, no discurso popular, "Ecologia" ser considerada (erroneamente) como sinônimo de "Ambientalismo" (ROSUMEK; MARTINS, 2010). Aqui, detectamos que este cenário ocorre também na maioria dos livros didáticos utilizados no Curso de Ciências Biológicas da FACEDI.

Concordamos com as reflexões de Rosumek e Martins (2010), ao defenderem que a conceituação delimitada é fundamental para à comunicação e que há sentido lógico na divisão do conhecimento por disciplinas, mas também concordamos com as preocupações destes autores de que isto não deve estimular a "fragmentação do conhecimento acadêmico, em que cada área é vista como distinta e precisamente definida em função de seus objetos de estudo ". Nesse contexto, registramos como ponto positivo o fato da maioria dos livros didáticos analisados apresentar a preocupação com a necessidade de síntese e integração de conhecimentos ambientais e ecológicos, mas por outro lado, o ponto negativo consiste em o fazerem em detrimento de delimitações conceituais corretas.

Por fim, assentimos com Voichicoski e Morales (2011) e Santos, Escovedo e Vilela (2014) que defendem a necessidade de pesquisas que relacionem o livro didático com o uso e concepções por parte dos professores e alunos. Por isso, discutiremos a seguir o contexto em que as definições de ecologia presentes nos livros didáticos são compreendidas pelos alunos do curso de Ciências Biológicas da FACEDI.

\subsection{Compreendendo as concepções de Ecologia em alunos de biologia em formação inicial}

Registramos que dos 97 alunos universitários que aceitaram participar da pesquisa, 50 ainda não cursaram nenhuma das disciplinas obrigatórias de Ecologia que são: Ecologia Geral - ofertada no $5^{\circ}$ semestres e Ecologia Regional - ofertada no $6^{\circ}$ semestres, enquanto 47 alunos já cursaram pelo menos uma das disciplinas.

Os alunos foram questionados sobre qual dos conceitos era o mais adequado, o primeiro conceito é o de Haekel e o segundo de Krebs, mas os alunos não tiveram acesso a essa informação no momento do questionamento. Com isso, foi registrado que nos semestres 
que antecedem a oferta das disciplinas de Ecologia ( $2^{\circ}$ e $4^{\circ}$ semestres), predominaram as marcações do conceito 1-Haeckel, mas a partir do $6^{\circ}$ semestre aumentou consideravelmente a quantidade de alunos que marcaram o conceito de Krebs (Fig. 1).

Os alunos que assinalaram a definição de Haeckel justificaram suas escolhas com base no conhecimento adquirido nos livros didáticos e no ensino médio, e aqueles que marcaram o conceito de Krebs, se utilizaram de justificativas mais diversificadas destacando o ensino superior como fonte de conhecimento.

Destacamos e transcrevemos algumas das justificativas dos alunos que marcaram a definição de Haeckel: "Acho que é um conceito mais estudado que eu lembre" (Aluno $2^{\circ}$ semestre); "O que aprendemos no ensino médio tem haver com esse conceito" (Aluno $2^{\circ}$ semestre); "É o conceito trazido nos livros didáticos e o que eu estudei no ensino médio" (Aluno $4^{\circ}$ semestre); "Não tenho certeza se estuda a distribuição" (Aluno $4^{\circ}$ semestre). "Acredito por ser um conceito simples e de fácil compreensão, seria o mais adequado para definir ecologia" (Aluno $10^{\circ}$ semestre). É possível que esse predomínio de definição de Haeckel seja em função da supremacia desse conceito nos livros didáticos, especialmente no ensino básico. No entanto, para Vasconcelos e Souto (2003), o livro didático deve ser um meio que promova a reflexão e estimule a capacidade investigativa do educando para que este assuma a posição de atuante na construção do seu conhecimento.

Dentre as justificativas que corroboram a definição de Krebs destacamos: "Pois é um termo mais técnico e apropriado para definir ecologia, abrangendo uma área vasta do conhecimento" (Aluno $4^{\circ}$ semestre). "Este conceito é o mais completo em relação ao outro, contudo para definir ecologia temos vários outros conceitos" (Aluno $6^{\circ}$ semestre). "Esse conceito de Krebs engloba as interações dos seres vivos com o seu ambiente e também os padrões e processos que são as interações e distribuição dos organismos nos ambientes" (Aluno $6^{\circ}$ semestre). "Porque além de estudar os seres vivos e o ambiente a ecologia também estuda como esses organismos estão distribuídos e sua abundancia e interações destes no meio.” (Aluno $8^{\circ}$ semestre). "Quando começamos a estudar ecologia no ens. superior nossa visão muda, é ensinado muito mais além do que vimos no ens. médio" (Aluno $10^{\circ}$ semestre). 
Figura 1 - Conceito de Ecologia na percepção de alunos de Biologia da UECE-FACEDI. Conceito 1= A Ecologia é a ciência que estuda as interações dos seres vivos com seu ambiente, Haeckel; Conceito 2= A Ecologia é o estudo cientifico das interações que determina a distribuição e abundancia dos organismos, Krebs; $\mathrm{S}=$ semestre e IR= irregular.

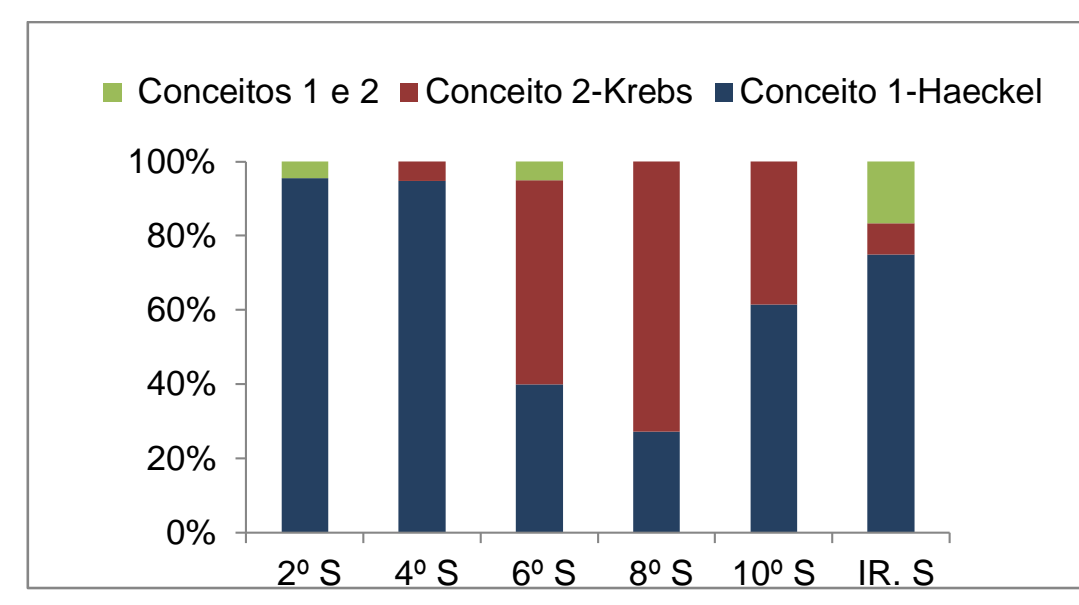

Fonte: Elabora pelas autoras

Os alunos foram também questionados sobre a autoria dos dois conceitos, mas apenas os que cursavam o $6^{0}$ e $10^{0}$ semestres responderam. No $6^{0}$ semestre, 95\% acertaram as autorias e $5 \%$ trocaram os autores, mas no $10^{\circ}$ semestre, $70 \%$ acertaram as autorias e $30 \%$ atribuíram a autoria dos dois conceitos a Raven. Um aluno nessa situação deu a seguinte justificativa: "É o conceito que lembro do livro de Raven" (Aluno 10 semestre). O referido livro é de Biologia Vegetal e por isso não foi incluindo na nossa análise. Este livro dedica uma secção ao assunto Ecologia e nela apresenta o seguinte conceito "A ecologia é frequentemente definida como o estudo das interações dos organismos uns com os outros e com o seu ambiente físico, mas é mais simples defini-la como o estudo dos sistemas ecológicos ou ecossistemas" (RAVEN; EVERT; EICHHORN, 2007 p.707). Os autores não citam a autoria do conceito e é possível que por isso os alunos tenham atribuído a autoria a Raven.

Quando indagados sobre o local de aquisição do conhecimento ficou evidente a influência da escola básica nos semestres iniciais e da faculdade a partir do $6^{0}$ semestre (Fig. 2). Podemos inferir com base nesse resultado que as disciplinas de Ecologia e Ecologia Regional estão contribuindo para a ampliação do repertório dos alunos participantes da pesquisa no que diz respeito aos conceitos de Ecologia. Podemos também assegurar que a faculdade tem um papel fundamental na concepção mais atualizada dos alunos acerca da Ecologia, analisando as respostas dos alunos sobre o local de aquisição de conhecimentos. 
Figura 2 - Local de aquisição de conhecimentos sobre o conceito de Ecologia, destacados pelos alunos de Biologia da UECE-FACEDI. Outros= jornais, revistas, televisão e internet; $S=$ semestre e IR= irregular.

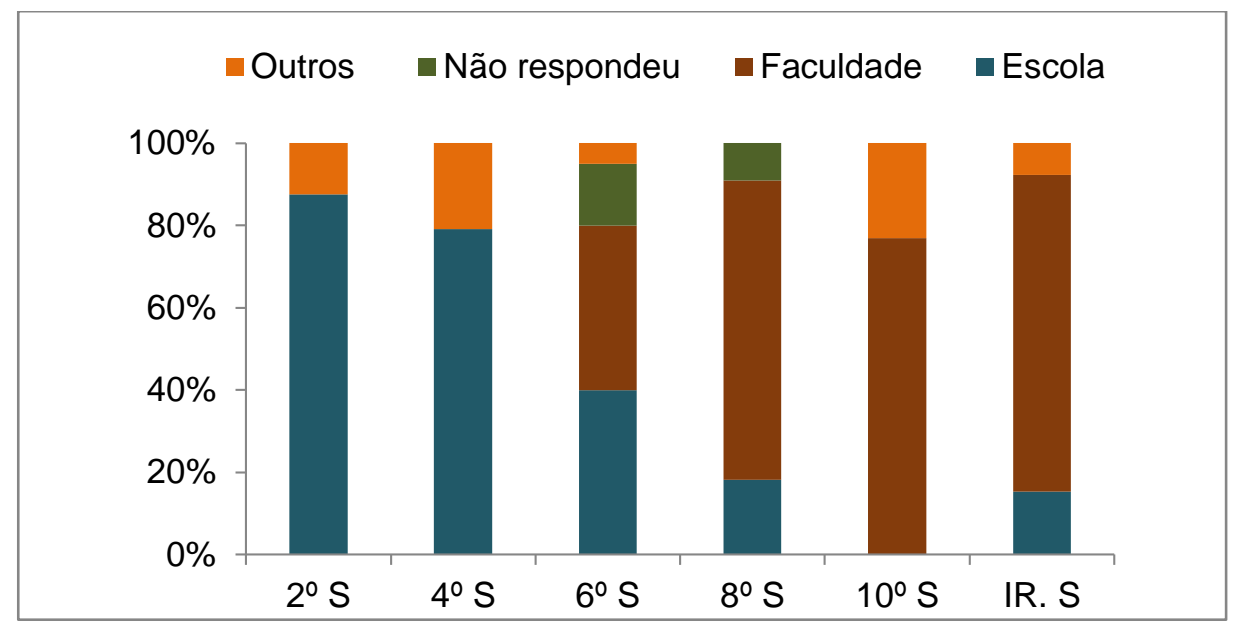

Fonte: Elaborada pelas autoras

Solicitamos também que os alunos descrevessem o que entendem por Ecologia. Com base nas respostas verificamos que $85 \%$ conceituaram Ecologia com definições que se aproximam do conceito de Haeckel, apenas $12 \%$ utilizaram definições semelhantes à de Krebs e 3\% não responderam (Fig. 3). A seguir são transcritos duas definições apresentadas pelos alunos e categorizadas como semelhante as definições de Haeckel e de Krebs, respectivamente: "É uma ciência, onde estuda as diversas relações e interações entre seres vivos e seu ambiente" (Aluno $10^{\circ}$ Semestre - categorizada como Haeckel); "Ecologia corresponde a um ramo das ciências biológicas que irá estudar as formas como os organismos estão distribuídos no meio, buscando compreender os fatores que condicionam essa distribuição" (Aluno $6^{\circ}$ Semestre - categorizada como Krebs).

Esses dados demonstram que quando os alunos conceituaram Ecologia, as porcentagens das definições categorizadas como de Krebs foram pequenas (Fig. 3), e ainda menores do que aquelas registradas quando os conceitos eram apresentados e o aluno tinha apenas que marcar qual o mais adequado (Fig. 1). Isso indica que nas duas situações a percepção da maior parte dos alunos, principalmente daqueles que ainda não cursaram as disciplinas de Ecologia, é mais próxima do conceito de Haeckel, e revela também que a compreensão do conceito de Krebs é ainda parcial, mesmo para aqueles alunos que já cursaram a disciplina de Ecologia e reconheceram tal conceito como o mais adequado. É possível que essa compreensão de Ecologia se deva ao fato de que o conceito de Haeckel predominou nos livros didáticos analisados e utilizados pelos sujeitos desta pesquisa. 
Figura 3 - Definições de Ecologia na concepção dos alunos de Biologia da UECE-FACEDI. Respostas categorizadas nos conceitos de Haeckel e Krebs. S= semestre e IR= irregular.

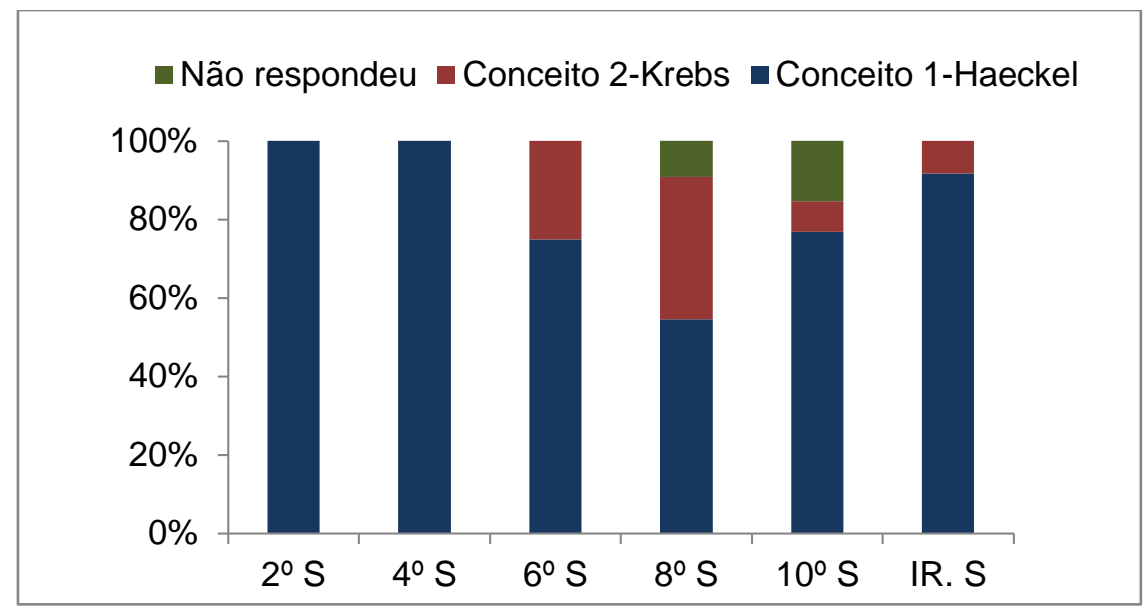

Fonte: Elaborada pelas autoras

A falta de uma reflexão sobre a evolução dos conceitos, objetivos e métodos da Ecologia, Ciências Ambientais e Educação Ambiental causa uma confusão conceitual que é disseminada e difundida entre os alunos, principalmente se o professor se limitar ao conteúdo do livro didático. Nesse contexto é prejudicial tanto para a Ecologia, quanto para as Ciências Ambientais e a Educação Ambiental. A esse respeito Correia destaca que:

[...] a abordagem sobre conhecimentos ecológicos nos livros se apresenta como uma tentativa de introdução da Educação Ambiental nas escolas públicas recifenses, ou seja, a Educação Ambiental está sendo confundida com o ensino da Ecologia (ciência), mesmo que não se apresente nestes livros uma relação direta entre Educação Ambiental e Ecologia. (CORREIA, 2014, p. 85).

Por fim foi perguntado aos alunos se eles consideram importante abordar essa temática na educação básica. Todos disseram que sim. A maioria destacou que a importância do conhecimento sobre os conceitos de Ecologia é fundamental para a compreensão de mundo e para preservar a natureza (Tabela 2). 
Tabela 2 - Importância da abordagem dos conceitos de Ecologia na educação básica de acordo com os alunos de Biologia da UECE-FACEDI. 1 = fundamental para a compreensão de mundo; 2 = fundamental para o vestibular; 3= faz parte do conteúdo programático do livro; 4= fundamental para preservar a natureza e 5= sem resposta.

\begin{tabular}{lccccc}
\hline & \multicolumn{5}{c}{ CATEGORIAS DEFINIDAS A POSTERIORI } \\
\hline & 1 & 2 & 3 & 4 & 5 \\
\cline { 2 - 6 } $2^{\circ}$ Semestre & $46 \%$ & $18 \%$ & $9 \%$ & $4 \%$ & $23 \%$ \\
$4^{\circ}$ Semestre & $69 \%$ & $5 \%$ & - & $21 \%$ & $5 \%$ \\
$6^{\circ}$ Semestre & $70 \%$ & $20 \%$ & - & $5 \%$ & $5 \%$ \\
$8^{\circ}$ Semestre & $73 \%$ & - & - & - & $27 \%$ \\
$10^{\circ}$ Semestre & $46 \%$ & $16 \%$ & - & $23 \%$ & $15 \%$ \\
Semestre irregular & $84 \%$ & - & - & $8 \%$ & $8 \%$ \\
\hline & Fonte: Elaborado pelas autoras
\end{tabular}

A representação que a maioria dos alunos tem a respeito da Ecologia está de acordo com o conceito de Haeckel, aprendido desde a educação básica e muitas vezes expresso de maneira mecânica. Sabemos que o processo de ensino aprendizagem não se dá apenas em decorar conceitos, mas sim em proporcionar habilidades e capacidades intelectuais que favoreçam uma relação crítica e reflexiva com os conteúdos abordados. Isso pode ser estimulado com o uso de múltiplas estratégias metodológicas e recursos didáticos diversificados. Perticarrari et al. (2010), por exemplo, utilizaram textos de divulgação científica para o ensino de conceitos sobre Ecologia na educação básica. Eles concluíram que "o uso de texto adequadamente preparado, associado à ação do professor como mediador, interferindo no processo cognitivo, possibilitou que os alunos fossem além do conhecimento de terminologias e fatos, importantes para a aprendizagem significativa". Este é um desafio para o professor, refletir sobre sua prática para buscar melhorá-la. Melhoria que pode ocorrer por meio de processos de ensino múltiplos do ponto de vista de metodologias e recursos.

Fica claro que os recursos para além do livro didático podem fazer toda a diferença. Por isso o professor pode variar a utilização dos recursos e metodologias didáticos, levando em consideração a adequação em cada momento ou cada fase do processo de ensino para atrair, contribuir e melhorar o ensino e a aprendizagem (KRASILCHIK, 2008). Porém, é necessário que o professor esteja preparado, capacitado, e tenha criatividade para explorar os benefícios que os recursos podem lhe proporcionar (BIZZO, 2009). Contudo, a utilização de qualquer estratégia metodológica deve ser feita com o intuito de proporcionar reflexões que levem o aluno à compreensão da realidade.

\section{Considerações Finais}

A despeito da existência de dezenas de diferentes definições de Ecologia, aquelas cunhadas por Haeckel e Krebs representam pontos importantes de delimitação do escopo, dos 
métodos e dos objetivos da ecologia e por isso entendemos que estas são definições que deveriam estar presentes nos livros didáticos. Na ausência destas definições cabe ao professor, principalmente quando for lecionar o conteúdo de Ecologia, citar, contextualizar e explicar diferentes definições de Ecologia.

Por fim, é importante destacar que não intencionamos polarizar uma discussão que fomente a oposição entre Ecologia, Ciências Ambientais e Educação Ambiental. Ao invés disso procedemos a uma reflexão do entendimento de quais são as particularidades de cada área para que a partir de disso seja possível uma condução de saberes, que exige além da compreensão dos conceitos isolados, o entendimento da articulação entre eles. Articulação essa que pode se dar por meio da interdisciplinaridade no ensino de Ciências e Biologia tanto na formação inicial dos professores quanto nas suas atuações profissionais.

\title{
REPRESENTATIONS OF THE CONCEPT OF ECOLOGY: ANALYSIS OF DIDACTIC BOOKS AND CONCEPTION OF STUDENTS OF BIOLOGICAL SCIENCES
}

\begin{abstract}
Ecology is a science that has different definitions the most used are those of Haeckel and Krebs, contrasting from a temporal and conceptual point of view. Therefore, we propose to: i) record the definitions of ecology present in the textbooks used at the State University of Ceara, the Faculty of Education of Itapipoca UECE/FACEDI and at the primary schools of Itapipoca-Ceara and ii) access the representations of the term Shared Ecology by the FACEDI Biology students who have already studied Ecology and those who have not yet studied them. With a descriptive quantitative-qualitative approach, we analyzed 35 books, 15 university students and 20 books of basic education. To verify which concepts are understood by the licensees we use a questionnaire, answered by 97 university students and analyzed by the content analysis method. We note that most of the books (27) contained only Haeckel's definition and used the term Ecology as synonymous with Environmental Sciences; Only seven books had the two definitions and only one contains only Krebs. These data demonstrate that the definition of Krebs is less widespread than that of Haeckel, and this adds to a conceptual limitation when considering Ecology as synonymous with Environmental Sciences, although both have a different scope. We also note that the perceptions of Ecology shared by students are closer to Haeckel's definition. We conclude that the conceptual inconsistency widely diffused in textbooks is also shared by the students, especially those who have not yet studied the subjects of Ecology.
\end{abstract}

Keywords: Teaching Ecology. Didactic Transposition. Haeckel. Krebs.

\section{Referências}

AMABIS, J. M.; MARTHO, G. R. Biologia das Populações. v. 3, São Paulo: Moderna, 2010 .

AMABIS, J. M.; MARTHO, G. R. Conceitos de biologia. v. 3, São Paulo: Moderna, 2001. 
BARDIN, L. Análise de Conteúdo. São Paulo: Edições 70, 2011.

BEGON, M.; TOWNSEND, C. R.; HARPER, J. L. Ecologia: de indivíduos a ecossistemas. 4 ed. Porto Alegre: Artmed, 2007.

BIZZO, N. Mais ciência no ensino fundamental: metodologia de ensino em foco. São Paulo: Editora do Brasil, 2009.

BRASIL. MINISTÉRIO DA EDUCAÇÃO. Orientações curriculares para o ensino médio. Ciências da Natureza, Matemática e suas Tecnologias. 2006.

CAIN, M. L.; BOWMAN, A. D.; HACKER, S. D. Ecologia. Porto Alegre: Artmed. 2011.

CELSO, M. Biogeografia e Ecologia. 5 ed. São Paulo: Nobel, 1985.

CÉSAR, S. J.; SEZAR, S. Biologia. 7 ed. São Paulo: Saraiva, 2005.

CÉSAR, S. J.; SEZAR, S. Biologia: Genética, Evolução e Ecologia. v. 3, São Paulo: Saraiva, 1995.

CHARBONNEAU, J. P.; CORAJOUD, M. C.; DAGT, J.; DAJOZ, R. Enciclopédia de Ecologia. São Paulo: EPU, 1979.

CIANCIARUSO, M. V.; SILVA, I. A.; BATALHA, M. A. Diversidades filogenética e funcional: novas abordagens para a Ecologia de comunidades. Biota Neotropica, v. 9, n. 3, p.93-103, 2009. Disponível em:

<http://www.biotaneotropica.org.br/v9n3/pt/abstract?article+bn01309032009 ISSN 16760603>. Acesso em: 24 out. 2017.

CORREIA, B. S. O. Representações do termo ecologia em uma amostra de livros didáticos da rede pública do recife: uma reflexão para a prática da educação ambiental. Revista Sergipana de Educação Ambiental, v. 1, n. 1, p. 69-87, 2014. Disponível em:

<https://seer.ufs.br/index.php/revisea/article/view/3208>. Acesso em: 24 out. 2017.

CRUZ, J. L. C. Projeto Araribá. Ciências. 2 ed. São Paulo: Moderna, 2007.

CURTIS, H. Biologia. 2 ed. São Paulo: Guanabara, 1997.

FERRI, M. G. Ecologia Geral. 3 ed. Belo Horizonte: Itatiaia, 1980.

FONSECA, G.; CALDEIRA, A. M. Uma reflexão sobre o ensino aprendizagem de ecologia em aulas práticas e a construção de sociedades sustentáveis. Revista Brasileira de Ensino de Ciência e Tecnologia, v. 1, n. 3, p. 70-92, 2008. doi:10.3895/S1982-873X2008000300006

FROTA-PESSOA, O. Os caminhos da vida: biologia no ensino médio. Ecologia e reprodução. São Paulo: Scipione, 2001.

GERMANO, M. G. Uma nova ciência para um novo senso comum. São Paulo: EDUEPB, 2011. 
GEWANDSZNAJDER, F. Ciência: o planeta terra. São Paulo: Ática, 2006.

GEWANDSZNAJDER, F. Ciência: planeta terra. São Paulo: Ática, 2013.

GOTELLI, N. J. Ecologia. 3 ed. Londrina: Planta, 2007.

GOWDAK, D.; MARINS, E. Coleção ciências, novo pensar. 5 série, São Paulo: FTD, 2002.

GRISI, B. M. Glossário de ecologia e ciências ambientais. 2 ed. João Pessoa: Editora Universitária UFPB, 2000.

GUREVITCH, J.; SCHEINER, S. M.; FOX, G. A. Ecologia Vegetal. 2 ed. Porto Alegre: Artmed, 2009.

HAECKEL, E. H. Generelle Morphologie der Organismen allgemeine Grundzuge der organischen Formen-Wissenschaft, mechanisch begrundet durch die von Charles Darwin reformirte Descendenz-Theorie von Ernst Haeckel: v.2. Verlag von Georg Reimer, 1866.

KRASILCHIK, M. Prática de Ensino de Biologia. São Paulo: Editora da Universidade de São Paulo, 2008.

KREBS, C. J. Ecology after 100 years: progress and pseudoprogress. New Zealand Journal of Ecology, v. 30, p. 3-11, 2006. Disponível em <http://www.jstor.org/stable/24056159>. Acesso em: 24 out. 2017.

KREBS, C. J. Ecology: the experimental analysis of distribution and abundance. New York: Harper International, 1972.

KUHN, T. A estrutura das revoluções científicas. 9 ed. São Paulo: Perspectiva, 2006.

LAURENCE, J. Biologia origem da vida e ecologia. São Paulo: Nova Geração, 1999.

LINHARES, S.; GEWANDSZNAJDER, F. Biologia hoje: genética, evolução e ecologia. v. 3, 11 ed. São Paulo: Ática, 2003.

LOPES, S. Bio3: genética, evolução e ecologia. 2 ed. São Paulo: Saraiva, 1992.

MALHEIROS, B. T. A Pesquisa Científica em Educação. In: (org.) RAMAL, A.

Metodologia da Pesquisa em Educação (pp.21-38). Rio Janeiro: LTC, 2011.

MARCONDES, A. C.; LAMMOGLIA, D. A. Biologia Ciência da vida: genética, evolução, ecologia. v. 3, São Paulo: Atual, 1994.

MARCZWSKI, M. Ciências biológicas. v. 3. São Paulo: FTD, 1999.

MARTINS, R. P.; LIMA, C. A. O desenvolvimento da ecologia no Brasil. Desenvolvimento e Meio Ambiente, v. 1, p. 83-86, 2000. Disponível em:

<http://revistas.ufpr.br/made/article/download/3059/2450>. Acesso em: 24 out. 2017. 
MAYR, E. Isto é biologia: a ciência do mundo vivo. São Paulo: Comp. das Letras. 2008.

MENEZES, B. S.; MARTINS, F. R.; ARAÚJO, F. S. Montagem de comunidades: conceitos, domínio e estrutura teórica. 2017. Oecologia Australis, v. 20, n. 1, p. 1-17. 2016. Disponível em: <10.4257/oeco.2016.2001.01>. Acesso em: 24 out. 2017.

MINISTÉRIO DA SAÚDE. Manual operacional para comitês de ética em pesquisa. 4. ed. Brasília: Conselho Nacional de Saúde, 2008.

MORAES, R. Análise de conteúdo. Revista Educação, v. 22, n. 37, p. 7-32, 1999.

MOREIRA, H.; CALEFFE, L G. Classificação da pesquisa. In: Metodologia da Pesquisa para o Professor Pesquisador (pp. 69-94). Rio de Janeiro: DP\&A, 2006.

ODUM, E. P. Ecologia. 4 ed. Rio de Janeiro: Guanabara Koogan, 1988.

PAULINO, W. R. Biologia Atual. v.3. 10ª ed. São Paulo: Ática, 2000.

PENA, M. Biologia pré-universitário anual. Modulo IV Ecologia. Fortaleza: FB, 2014.

PERTICARRARI, A.; TRIGO, F. R.; BARBIERI, M. R.; COVAS, D. T. O uso de textos de divulgação científica para o ensino de conceitos sobre ecologia a estudantes da educação básica. Ciência \& Educação, v. 16, n. 2, p. 369-386, 2010. Disponível em:< http://www.scielo.br/pdf/ciedu/v16n2/v16n2a07>. Acesso em: 24 out. 2017.

PINTO-COELHO, R. M. Fundamentos em ecologia. Porto Alegre: Artmed, 2002.

POPPER, K. R. A lógica da pesquisa científica. São Paulo: Editora Cultrix, 1985.

PURVES, W. K.; SADAVA, D.; ORIANS, G. H.; HELLER, H. C. Vida: a ciência da biologia: evolução, diversidade e ecologia. v. 2, 6 ed. Porto Alegre: Artmed, 2005.

RAVEN, P. H.; EVERT, R. F.; EICHHORN, S. E. Biologia vegetal. 5 ed. Rio de Janeiro, Guanabara Koogan, 2001.

RICKLEFS, R. E. A Economia da Natureza. 5 ed. Rio de Janeiro: Guanabara Koogan, 2003.

ROSUMEK, F. B.; MARTINS, R. P. Ecologia, filosofia e conservação. Natureza \& Conservação, v. 8, n. 1, p. 87-89, 2010. doi: 10.4322/natcon.00801015

RUFATTO, C. A.; CARNEIRO, M. C. A concepção de ciência de Popper e o ensino de ciências. Ciência \& Educação, v. 15, n. 2, p. 269-289, 2009.

SANTOS, F. S.; AGUILAR, J. B. V.; OLIVEIRA, M. M. A. Biologia ser protagonista. v. 3. São Paulo: Edições SM, 2010.

SANTOS, R. M.; ESCOVEDO, S. L.; VILELA, M. L. Conhecimento científico e escolar no ensino de ecologia: a dualidade entre paradigmas ecológicos em um livro didático. Revista de Ensino de Biologia da SBEnBio, n. 7, p. 6619-6628, 2014. 
SILVA, N. S.; EL-HANI, C. N. A abordagem do tema Ambiente e a formação do cidadão socioambientalmente responsável. Revista Brasileira de Pesquisa em Educação em Ciências, v. 14, n. 2, p. 225-234, 2014.

SILVA, T. C.; ALBUQUERQUE, U. P. O que é percepção ambiental. In: ALBUQUERQUE, U. P. (Org.) Introdução a Etnobotânica (pp. 55-58). Recife: Nupea, 2014.

SILVEIRA, E. L.; GEALH, A. M.; MORALES, A. G.; CALDEIRA, C. S. Análise do conteúdo de zoologia de vertebrados em livros didáticos aprovados pelo PNLEM 2009. Revista Brasileira de Pesquisa em Educação em Ciências, 13(1), 217-232. 2013.

SOARES, J. L. Biologia. 9 ed. São Paulo: Scipione, 1997.

SOARES, J. L. Biologia: genética, evolução, ecologia. v. 3. São Paulo: Scipione, 2000.

TOWNSEND C. R.; BEGON, M.; HARPER, J. L. Fundamentos em Ecologia. 2 ed. Porto Alegre: Artmed, 2006.

UZUNIAN, A.; BIRNER, E. Biologia 3. São Paulo: Harbra, 1997.

VASCONCELOS, S. D.; SOUTO, E. O Livro didático de ciências no ensino fundamental proposta de critérios para analise do conteúdo zoológico. Ciência \& Educação, v. 9, n. 1, p. 93-104, 2003. Disponível em: < http://www.scielo.br/pdf/ciedu/v9n1/08>. Acesso em: 24 out. 2017.

VOICHICOSKI, M. S. R.; MORALES, A. G. Análise das pesquisas recentes (2000 a 2010): da relação entre educação ambiental e livro didático. Olhar de Professor, v. 14, n. 2, p. 239$254,2011$. 